\title{
Evaluation of Genetic Diversity Among 'Candidatus Liberibacter asiaticus' Isolates Collected in Southeast Asia
}

\author{
Kenta Tomimura, Shin-ichi Miyata, Noriko Furuya, Kenji Kubota, Mitsuru Okuda, \\ Siti Subandiyah, Ting-Hsuan Hung, Hong-Ji Su, and Toru Iwanami
}

First author: Kuchinotsu Citrus Research Station, National Institute of Fruit Tree Science, Kuchinotsu, Minami-shimabara, Nagasaki 8592501, Japan; second, third, and ninth authors: National Institute of Fruit Tree Science, Fujimoto 2-1, Tsukuba, Ibaraki 305-8605, Japan; fourth and fifth authors: National Agricultural Research Center for Kyushu Okinawa Region, Suya 2421, Koshi, Kumamoto 861-1192, Japan; sixth author: Department of Entomology and Plant Pathology, Gadjah Mada University, Yogyakarta 55281, Indonesia; seventh and eighth authors: Department of Plant Pathology and Microbiology, National Taiwan University, Taipei 106, Taiwan.

Accepted for publication 29 April 2009.

\begin{abstract}
Tomimura, K., Miyata, S.-I., Furuya, N., Kubota, K., Okuda, M., Subandiyah, S., Hung, T.-H., Su, H.-J., and Iwanami, T. 2009. Evaluation of genetic diversity among 'Candidatus Liberibacter asiaticus' isolates collected in Southeast Asia. Phytopathology 99:1062-1069.

The aim of this study was to investigate the genetic diversity and relationships among 'Candidatus Liberibacter asiaticus' isolates from different hosts and distinct geographical areas in Southeast Asia. Genetic diversity among ' $\mathrm{Ca}$. Liberibacter asiaticus' was estimated by sequencing four well-characterized DNA fragments: the $16 \mathrm{~S}$ ribosomal DNA (rDNA) and $16 \mathrm{~S} / 23 \mathrm{~S}$ intergenic spacer regions; the outer membrane protein (omp) gene region; the trmU-tufB-secE-nusG-rplKAJL-rpoB region (gene cluster region); and the bacteriophage-type DNA polymerase region. The sequences of the 16S rDNA and 16S/23S intergenic spacer regions were

nucleotide substitutions were observed in both the omp gene and the gene cluster regions. However, extended bacteriophage-type DNA polymerase sequences acquired by thermal asymmetric interlaced polymerase chain reaction provided the most sequence diversity among isolates. Phylogenetic analysis of the bacteriophage-type DNA polymerase sequences revealed three clusters in the Southeast Asian ' $\mathrm{Ca}$. Liberibacter asiaticus' population. All Indonesian ' $\mathrm{Ca}$. Liberibacter asiaticus' isolates clustered in one group. The other clusters were not correlated with geographic distribution. The differences in genetic sequences did not reflect differences in the original citrus host (mandarin or pummelo). These results suggest that the bacteriophage-type DNA polymerase region would be useful for molecular differentiation between different Southeast Asian ' $\mathrm{Ca}$. Liberibacter asiaticus' isolates.
\end{abstract} identical among all ' $\mathrm{Ca}$. Liberibacter asiaticus' isolates. In contrast,
Additional keywords: citrus greening.
Citrus greening (Huanglongbing) is one of the most destructive diseases that affect citrus trees in many parts of the world (Asia, North America, South America, and Africa). Citrus greening is a threat to the citrus production industry (9). The causal agents of this disease are 'Candidatus Liberibacter spp.', which are gramnegative, phloem-limited bacteria. The first cultivation of some isolates of these bacteria have been just reported (27). The pathogens are transmitted by the psyllids Trioza erytreae in Africa (2) and Diaphorina citri in Asia, North America, and South America (13). Compared with D. citri, T. erytreae is found in cooler areas and at higher altitudes. D. citri is more widely spread in warmer lowlands in tropical and subtropical areas. These pathogens are also transmitted by contaminated plant materials used for propagation of nursery plants. Three ' $C a$. Liberibacter spp.' that act as pathogens have been identified: ' $C a$. Liberibacter asiaticus', ' $C a$. Liberibacter africanus' (16), and ' $C a$. Liberibacter americanus' (8).

\section{Corresponding author: T. Iwanami; E-mail address: tiwsw37@affrc.go.jp}

The nucleotide sequence data reported in this article have been deposited in the DDBJ, EMBL, and GenBank databases with the following accession numbers: AB473569-AB473597 and AB480072-AB480161.

* The $e$-Xtra logo stands for "electronic extra" and indicates that the online version contains a supplemental table showing the variable nucleotides in the omp gene region, the trm $\mathrm{U}-t u f \mathrm{~B}-s e c \mathrm{E}-n u s \mathrm{G}-r p l \mathrm{KAJL}-r p o \mathrm{~B}$ region, and the bacteriophagetype DNA polymerase region among 'Candidatus Liberibacter asiaticus' isolates.

doi:10.1094/PHYTO-99-9-1062

(C) 2009 The American Phytopathological Society
Infected citrus trees show various symptoms, mainly on their leaves and fruit. However, none of the symptoms are specific to citrus greening (6). In Japan, this disease was found for the first time in the southern-most islands in 1988 (23). Since then, the disease has spread northward to the main production areas where it poses a great threat to domestic citrus cultivation. Citrus greening is still limited to relatively few orchards and backyard gardens in Japan, and it is managed by the removal of infected trees at the early stages of infection.

Assessment of genetic diversity provides a framework for understanding the taxonomy, population structure, and dynamics of phytobacteria. It also provides a key for devising sensitive, specific, and rapid methods for detecting the pathogen, diagnosing plant disease, and managing disease risk (22). Methods to distinguish ' $\mathrm{Ca}$. Liberibacter asiaticus' isolates are fundamental for ecologic and epidemiologic studies. In epidemiology, the knowledge of genetic variation in the pathogen is important for determining the source of the infection. Molecular techniques are considered to be the most accurate means of fingerprinting microorganisms on a species and subspecies level (22). The comparison of ribosomal DNA (rDNA) sequences is a powerful tool for deducing phylogenetic and evolutionary relationships among bacteria, archaebacteria, and eukaryotic organisms (32). The bestcharacterized regions of ' $\mathrm{Ca}$. Liberibacter spp.' are the $16 \mathrm{~S}$ rDNA and $16 \mathrm{~S} / 23 \mathrm{~S}$ intergenic spacer regions $(15,16,24,29)$. For several Japanese, Philippine, and Indonesian isolates, the nucleotide sequences of these regions are identical. The sequences of these isolates are similar to those from India and China and are distinct from those from Africa (24,29). Thus, comparison of ' $\mathrm{Ca}$. 
Liberibacter asiaticus' isolates using these genomic sequences has shown little variation among isolates.

A potential gene locus for evaluation is the gene that codes for the outer membrane protein (omp), which has a few nucleotide differences among the isolates (3). The strains isolated from pummelo plants in China were highly homogeneous (10). A third candidate for discriminating between strains of ' $\mathrm{Ca}$. Liberibacter asiaticus' is the nusG-rplKAJL-rpoB gene cluster (31). These cluster sequences were extended by Okuda and colleagues (24) and Lin and colleagues (19). However, little is known about the genetic sequence diversity of these gene clusters among ' $\mathrm{Ca}$. Liberibacter asiaticus' isolates. Okuda and colleagues (24) showed that there were a few nucleotide differences between the Japanese and Indonesian isolates. These previous reports indicated some genetic variation among ' $\mathrm{Ca}$. Liberibacter asiaticus' isolates but these differences were insufficient to discuss intraspecies genetic diversity. The other potential gene locus for evaluation is the bacteriophage-type DNA polymerase region. It became increasingly clear that prophage DNA has played an important role in the evolution of bacterial pathogenicity (7). This region had been characterized as the DNA polymerase of Bacillus subtilis bacteriophage SPO2 (31) and not characterized largely thereafter. Also, this bacteriophage belongs to Siphoviridae, an unclassified Lambda-like virus.

Knowledge about the genetic diversity of ' $\mathrm{Ca}$. Liberibacter asiaticus' from different geographical areas and citrus cultivars is indispensable for the management of disease risk. However, there have been few reports about this diversity. Of the isolates examined in the present study, five isolates from Taiwan were carefully examined for pathogenicity in citrus cultivars (30). These isolates had remarkably different pathogenicity among the cultivars. It is unknown whether these biological differences reflect genomic variation. Thus, these isolates from Taiwan were included in this study.

The objectives of this study were to determine the genetic diversity among ' $\mathrm{C}$ a . Liberibacter asiaticus' isolates using several gene regions. The relation between genetic diversity and the geographic origin of the isolates and citrus cultivars was investigated. The results suggest that the polymorphic bacteriophagetype DNA polymerase region may be useful for molecular differentiation among the Southeast Asian ' $C a$. Liberibacter asiaticus' isolates.

\section{MATERIALS AND METHODS}

Isolation of genomic DNA from ' $\boldsymbol{C a}$. Liberibacter asiaticus'. Except for sources of isolates from Japan (OK901 and KIN1) and Taiwan (TW1, 2, 3, 5, and 6) that were maintained on rough lemon or sweet orange trees in a greenhouse, field plants from Vietnam, Thailand, Indonesia, and Japan were the sources of the genomic DNA from ' $\mathrm{Ca}$. Liberibacter asiaticus'. Leaf samples were collected from infected citrus trees (mandarin and pummelo) in different groves in subtropical and tropical regions of Southeast Asia (Table 1). Total DNA was extracted from $\approx 0.2 \mathrm{~g}$ of the leaf midrib from the infected citrus tree using a DNeasy Plant Mini kit (Qiagen, Valencia, CA) according to the manufacturer's instructions. The extracted DNA was suspended in 20 to $200 \mu \mathrm{l}$ of TrisEDTA buffer (10 mM Tris-HCl, 1 mM EDTA, pH 8.0).

Thermal asymmetric interlaced polymerase chain reaction. Thermal asymmetric interlaced polymerase chain reaction (TAILPCR) was performed to determine the nucleotide sequences of the regions adjacent to the tufB-secE-nusG-rplKAJL-rpoB gene cluster and the bacteriophage-type DNA polymerase region. The isolate IDN03-5 was used for the TAIL-PCR experiments. Specific primers for the regions upstream and downstream of the known sequences were used in combination with the short arbitrary degenerate (AD) primers reported by Liu and Whittier (21). The primary TAIL-PCR was carried out in a $20-\mu$ reaction mixture volumes containing $2 \mu \mathrm{l}$ of DNA template, $0.2 \mu \mathrm{M}$ specific primer, $5 \mu \mathrm{M}$ AD primer, $250 \mu \mathrm{M}$ dNTP mixture, $1 \times$ PCR buffer, and 1 unit of Ex Taq DNA polymerase Hot Start Version (TaKaRa, Japan). The resulting mixture was diluted 50 times and subjected to secondary PCR. Tertiary PCR was carried out using the secondary PCR template diluted 50 times. These rounds of TAIL-PCR cycling were performed in a GeneAmp PCR System 9600 (Applied Biosystems, Foster City, CA) with the condition reported previously $(21,24)$. The secondary and tertiary PCR products ( 7 of $20 \mu \mathrm{l}$ ) were separated by electrophoresis in an agarose gel. The specificity of the PCR products is confirmed by the expected overlapping of sequences between the known region and the TAIL-PCR product.

PCR amplification and sequencing. Amplification of the $16 \mathrm{~S}$-specific fragment from ' $C a$. Liberibacter asiaticus' was carried out using the primer pair OI1 and OI2c (Table 2) (29). The spacer intergenic region between $16 \mathrm{~S}$ and 23S rDNA was amplified using the primer pair OI2 and 23S1-rev (29). The reaction mixtures and thermal cycling conditions have been described (29). Amplification of a specific fragment from the omp region was performed using the primer pair OMP5F and OMP5R, which correspond to nucleotides 169 to 188 and 3081 to 3100 , respectively (GenBank accession no. AY642159) (3). Amplification of the trmU-tufB-secE-nusG-rplKAJL-rpoB region (gene cluster region), including newly obtained sequences by use of TAIL-PCR, was carried out using five primer pairs (Table 2). The resulting DNA fragment (GenBank accession no. M94320) contains the putative bacteriophage-type DNA polymerase region and is 988 nucleotides long. Based on this sequence, the primer pair GODNPFW1 and GODNPRV1 was designed (Table 2). Amplification of longer DNA polymerase regions was carried out to produce fragments 1 and 2 (Table 2; Fig. 1) using two primer pairs that were designed after the sequences of the flanking regions were determined by TAIL-PCR. The PCR reactions were performed using an iCycler thermal cycler (Bio-Rad Laboratories Hercules, CA) in $20-\mu \mathrm{l}$ reaction mixture volumes containing $2 \mu \mathrm{l}$ of DNA template, $1 \mu \mathrm{M}$ each primer, $200 \mu \mathrm{M}$ dNTP mixture, $1 \times$ PCR buffer, and 0.5 units of Ex Taq DNA polymerase Hot Start Version (TaKaRa). The thermal cycling conditions were as follows: initial denaturing at $94^{\circ} \mathrm{C}$ for $2 \mathrm{~min}$; 40 cycles of denaturing at $94^{\circ} \mathrm{C}$ for $30 \mathrm{~s}$, annealing at $50^{\circ} \mathrm{C}$ for $30 \mathrm{~s}$, and extension at $72^{\circ} \mathrm{C}$ for 1 min per kilobase of expected PCR product size; and a final extension step at $72^{\circ} \mathrm{C}$ for $5 \mathrm{~min}$. The amplified PCR products were separated by electrophoresis in an agarose gel and purified using the QIAquick Gel Extraction Kit (Qiagen) according to the manufacturer's instructions. Each purified PCR product was sequenced by primer walking in both directions using the BigDye Terminator v3.1 Cycle Sequencing Ready Reaction Kit (Applied Biosystems) and an Applied Biosystems Genetic Analyzer DNA Model 310. Sequence data were assembled using BioEdit version 5.0.9 (14).

Sequence analyses. The open reading frames (ORFs) of the bacteriophage-type DNA polymerase region were searched using GENETYX-WIN computer program (version 3.2.0; Hitachi, Japan). Each ORF sequence was compared with the EMBL and GenBank entries by use of BlastN and BlastX (1). The sequences of the 27 ' $\mathrm{Ca}$. Liberibacter asiaticus' isolates were first aligned using Clustal $X$ (17). The phylogenetic relationships of the sequences were determined by use of the neighbor-joining algorithm of PHYLIP (version 3.5) (12). For neighbor-joining analysis, a distance matrix was calculated by DNADIST with the Kimura two-parameter option (18). The tree was constructed from this matrix by use of the neighbor-joining method (26). A bootstrap value for each internal node of the neighbor-joining tree was calculated using 1,000 random resamplings with SEQBOOT (11). The calculated tree was displayed by use of TREEVIEW (25).

PCR amplification of fragments of the bacteriophage-type DNA polymerase region. After the sequence of the bacterio- 
phage-type DNA polymerase region was determined, five primer sets were designed to amplify various parts of this region. The sequences and positions of the primers are indicated in Table 2 and Figure 1.

\section{RESULTS}

Sequences of the 16S rDNA and 16S/23S intergenic spacer regions. Up to 31 isolates of ' $\mathrm{Ca}$. Liberibacter asiaticus' were collected throughout Southeast Asian countries (Table 1). The reference isolates reported previously were also listed in Table 1. Sequences of the $16 \mathrm{~S}$ rDNA and $16 \mathrm{~S} / 23 \mathrm{~S}$ intergenic spacer regions of 31 ' $\mathrm{Ca}$. Liberibacter asiaticus' isolates were determined and compared. The nucleotide sequences of these regions were compared with those previously reported for the isolates OK901, KIN1 (29), and Y02-57, as well as three Indonesian isolates (IDN03-2, IDN03-5, and IDN03-7) (24). All sequences except that from the India-Poona isolate were identical. Sequence differences observed in the India-Poona isolate consisted of 23 nucleotide changes, as reported by Subandiyah and colleagues (29).

Sequences of the omp gene region. The sequences of the omp gene region were determined. The sequences obtained from all 31 isolates were 2,832 nucleotides in length. When the omp gene region sequences were compared among the 31 isolates sequenced in this study, two nucleotide differences (positions 857 and 2415) were found (supplemental table). At nucleotide position 857, four Japanese isolates (OK901, KIN1, Y02-57, and Ishi1) and one Vietnamese isolate (V61) had adenine at this location whereas the other isolates had thymine at this location. This difference caused a nonsynonymous amino acid substitution from serine to threonine. Nucleotide change at position 2,415 was specific to four Japanese isolates (OK901, KIN1, Y02-57, and Ishi1). The Japanese isolates had an adenine while the other

TABLE 1. Isolates and field sources of 'Candidatus Liberibacter asiaticus' used in this study

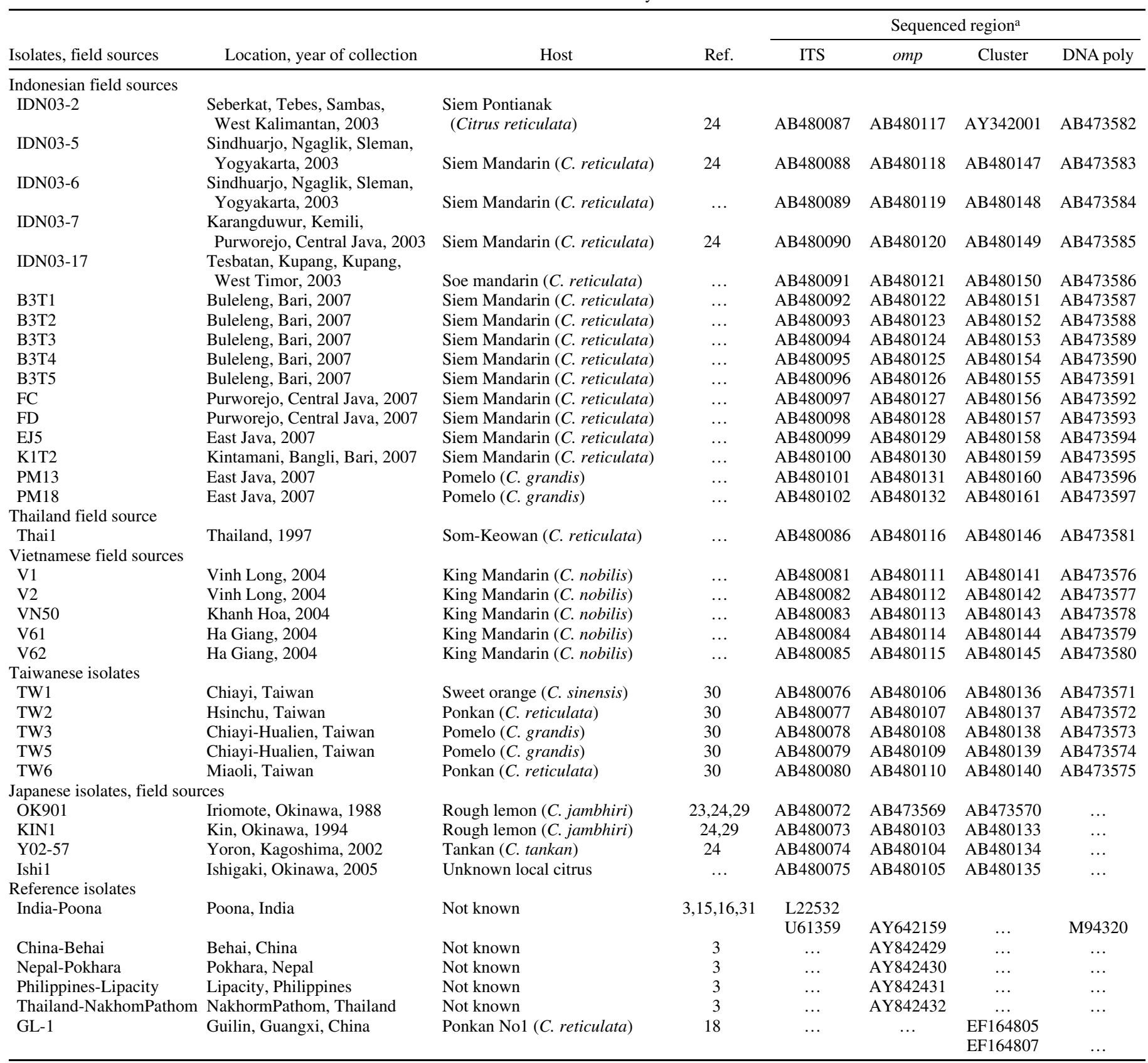

${ }^{\mathrm{a}} \mathrm{ITS}=16 \mathrm{~S}$ and $16 \mathrm{~S} / 23 \mathrm{~S}$ intergenic spacer regions, omp = the outer membrane protein gene region, Cluster $=$ the $t r m \mathrm{U}$-tufB-secE-nusG-rplKAJL-rpoB region, and DNA poly $=$ the bacteriophage-type DNA polymerase region. 
isolates had cytosine. This difference caused an amino acid substitution, also nonsynonymously, from threonine to asparagine.

The omp genes $(2,346$ nucleotides long) of the 31 isolates were compared with the five reference isolates of India-Poona, ChinaBehai, Nepal-Pokhara, Philippines-Lipacity, and ThailandNakhomPathom. Nucleotide differences were observed at 17 sites (supplemental table). Of the 17 nucleotide differences, 7 were specific to the India-Poona isolate, which suggests that this isolate is distinct from other isolates from Southeast Asia.

Sequences of the trmU-tufB-secE-nusG-rplKAJL-rpoB region. In an effort to identify additional sites of sequence diversity, we extended the genetic region of the nusG-rplKAJL-rpoB gene cluster (24); namely, 1,975 nucleotides from the $5^{\prime}$ end and 1,496 nucleotides from the $3^{\prime}$ end. The combined sequence was 9,616 nucleotides in length. The sequence consisted of several coding regions, beginning with a partial coding sequence for tRNA (5methylaminomethy-2-thiouridylate)-methyltransferase at the $5^{\prime}$ end and ending with a partial gene coding for RNA polymerase $\beta$ subunit at the $3^{\prime}$ end. This sequence formed the trmU-tufB-secE$n u s \mathrm{G}-r p l \mathrm{KAJL}-r p o \mathrm{~B}$ region (gene cluster region). The sequences of the gene cluster region (excluding the primer sequences at both ends), which were 9,575 nucleotides long, were analyzed for each isolate.

The nucleotide sequence of each isolate, except for the isolate IDN03-2, was determined. Because there was not enough DNA from IDN03-2 to amplify the gene cluster region, the sequence of the newly extended region could not be determined. Therefore, a partial sequence of IDN03-2 that had previously been published was used (24). The reference sequences (GenBank accession nos. EF164805 and EF164807) were used for comparison among the ' $C a$. Liberibacter asiaticus' isolates. These sequences were from the Chinese isolate GL-1 and corresponded to nucleotide posi- tions 1 to 3605 and 6521 to 9575 in the newly sequenced gene cluster regions.

When the sequences were compared among the 31 isolates and reference isolate GL-1, 13 nucleotide differences were found (supplemental table). Of these, eight differences were specific to only one isolate. Of the eight specific differences, six were in the isolate GL-1. The other specific differences were at nucleotide positions 3084 and 4259, which were unique to the isolates TW3 and TW2, respectively. The nucleotide differences in the intergenic region were observed at nucleotide positions 165 and 3084. A previous study (24) reported three nucleotide differences, which correspond to nucleotide positions 3760, 6966, and 8061 in this study. The results showed that polymorphisms at any nucleotide position in this region were not sufficient to determine the geographical origin of the ' $\mathrm{Ca}$. Liberibacter asiaticus' isolate. Of the 13 nucleotide differences, 6 were nonsynonymous. These amino acid differences were observed in the genes trm $\mathrm{U}$ (leucine to valine), tufB (lysine to arginine and histidine to arginine), $r p l \mathrm{~K}$ (proline to serine), and rpoB (isoleucine to threonine and cysteine to tyrosine).

Sequences of the bacteriophage-type DNA polymerase region. Previously, Villechanoux and colleagues (31) reported the partial sequence of the India-Poona isolate of the bacteriophagetype DNA polymerase gene, which was deposited in GenBank (accession no. M94320). In the present study, this region among 27 isolates, excluding the four Japanese isolates (OK901, KIN1, Y02-57, and Ishi1), was amplified and sequenced. The comparison of this region revealed that the India-Poona isolate was remarkably different from the other isolates. For example, the nucleotide identity was $91.9 \%$ between the India-Poona and IDN03-5 isolates. This region was amplified by use of TAIL-PCR with specific primers for the bacteriophage-type DNA poly-

TABLE 2. Oligonucleotide primers for polymerase chain reaction amplification used in this study

\begin{tabular}{|c|c|c|}
\hline Primer name ${ }^{\mathrm{a}}$ & Nucleotide sequences $\left(5^{\prime}-3^{\prime}\right)$ & Nucleotide position $^{\mathrm{b}}$ \\
\hline \multicolumn{3}{|l|}{$16 \mathrm{~S}$ rDNA } \\
\hline OI1 & GCGCGTATGCAATACGAGCGGCA & $39-61$ \\
\hline $\mathrm{OI} 2 \mathrm{c}$ & GCCTCGCGACTTCGCAACCCAT & $1,183-1,204$ \\
\hline OI2 & ATGGGTTGCGAAGTCGCGAGGC & $1,183-1,204$ \\
\hline 23S1-rev & CGCCCTTCTCTCGCGCTTGA & $\ldots$ \\
\hline \multicolumn{3}{|c|}{ ( } \\
\hline Omp5F & GCATTCTTGGCTATGTTTTC & $229-248$ \\
\hline FW38 & GAACTGATAGTCAAGACAGTG & -21 to -1 \\
\hline RV2127 & CCCGTAATTTCTCTTCTGGAGC & $2,042-2,063$ \\
\hline FW1991 & GGAGAGTCTTGGTCTCAGTAC & $1,927-1,947$ \\
\hline RV4101 & ACTCTACTGGTGTGACACG & $4,019-4,037$ \\
\hline FW3988 & GTGTCTCTGATGGTCCGTTTG & $3,924-3,944$ \\
\hline RV6199 & CGCAGAAGCAGAAACACCC & $6,117-6,135$ \\
\hline FW5978 & GGTACGCCACAGACTCAAGTTG & $5,914-5,935$ \\
\hline DNApoly3735FW28 & GAGGTGTTACCTACTCTTCGC & -21 to -1 \\
\hline DNP3735R600 & GTATCAAGAGCAGGGTACG & $533-551$ \\
\hline GODNPFW1 & TCCTGAGAATTACACACAAAC & $786-806$ \\
\hline GODNPRV1 & TCTAAGTCTATCCTGTAACCC & $1,746-1,766$ \\
\hline DNP3735F1632 & CTCCGTATGACTGTACTCGTGC & $1,583-1,604$ \\
\hline DNP3735R2390 & CTTCACCAGCAATCCATGCC & $2,322-2,341$ \\
\hline DNP3735R2060 & CCGATGATGCTAAGCGGTTC & $1,992-2,011$ \\
\hline GODNPTAFW1 & GGGGAGTACTGCAAACGAGAC & $1,633-1,653$ \\
\hline DNP3735R2934 & CAATCGCCCTTTACATCACTG & $2,865-2,885$ \\
\hline DNP3735F2534 & GGGGCTAAGGTGTTTAAGAC & $2,485-2,504$ \\
\hline DNApoly3735RV3680 & AAGGACAGGACGAGGATCAAG & $3,611-3,631$ \\
\hline
\end{tabular}

${ }^{a}$ rDNA = ribosomal DNA; ITS = intergenic spacer regions, with primers reported by Subandiyah and colleagues (28); omp = the outer membrane protein gene region; Cluster $=$ the $t r m \mathrm{U}-t u f \mathrm{~B}-s e c \mathrm{E}-n u s \mathrm{G}-r p l \mathrm{KAJL}-r p o \mathrm{~B}$ region; and DNA poly = the bacteriophage-type DNA polymerase region.

${ }^{\mathrm{b}}$ Nucleotide positions are numbered following the sequences in the GenBank database: AY642159 for the omp gene region, AB473570 for the gene cluster region, and AB473571 for the bacteriophage-type DNA polymerase region. 
merase, which amplified 807 nucleotides from the $5^{\prime}$ end and 1,858 nucleotides from the $3^{\prime}$ end of M94320. The combined sequence was 3,653 nucleotides long. Excluding the primer sequences from each end, the 3,610 nucleotide sequences were analyzed for each isolate (Fig. 1). The primers designed to amplify the whole region of the sequence detected a DNA fragment of the expected size from all except four Japanese isolates. This region was not amplified from the four Japanese isolates in spite of repeated attempts using five primer pairs which cover the overall region of the bacteriophage-type DNA polymerase (Fig. 2). Nucleotide sequence alignment showed that the sequences of the 27 isolates could be roughly classified into two sequence types. One type was 3,610 nucleotides long and the other was 3,609 nucleotides long. One nucleotide deletion was observed at nucleotide position 486 (supplemental table).

A phylogenetic tree was constructed based on the nucleotide sequences of the 27 isolates of ' $\mathrm{Ca}$. Liberibacter asiaticus' for which the bacteriophage-type DNA polymerase region could be amplified. The relationships among the isolates were investigated by neighbor-joining. The resultant tree was separated into three groups (Fig. 3, groups A, B, and C). All of the 16 Indonesian isolates belonged to group A. Although the isolates V62 (Vietnamese) and TW1 (Taiwanese) were in group A, most Vietnamese and Taiwanese isolates were in group B. Group C appears to be a minor group, consisting of only the isolates of Thail (Thailand) and VN50 (Vietnamese).

Four putative ORFs encoding proteins longer than 100 amino acids were identified from the obtained nucleotide sequences (Table 3). Of the four ORFs, the functions of ORF1, 2, and 4 were unknown. However, ORF3 was predicted to code for a DNA polymerase. In a previous study, Villechanoux and colleagues (31) suggested that the part of the bacteriophage-type DNA polymerase sequence was a SPO2-like DNA polymerase. The present study revealed complete amino acid sequence of this putative protein. ORF3 and ORF4 of the bacteriophage-type DNA polymerase region were similar to Bordetella phage BPP-1 coding proteins (20).

\section{DISCUSSION}

In this study, new sequences of the trmU-tufB-secE-nusG$r p l \mathrm{KAJL}-r p o \mathrm{~B}$ region and the bacteriophage-type DNA polymerase region of ' $\mathrm{Ca}$. Liberibacter asiaticus' were characterized, and genetic diversity among the ' $\mathrm{Ca}$. Liberibacter asiaticus' isolates, including these regions, was determined. The degree of genetic diversity was different in each analyzed region, and the most genetic diversity was found in the bacteriophage-type DNA polymerase region. The nucleotide sequence of this region allowed the ' $\mathrm{Ca}$. Liberibacter asiaticus' isolates to be separated into distinct groups, suggesting that these differences could be used to differentiate between the Southeast Asian ' $\mathrm{Ca}$. Liberibacter asiaticus' isolates.

TAIL-PCR is the one of the most efficient methods used to obtain unknown sequences adjacent to known sequences (21). Two regions (the gene cluster region and the bacteriophage-type DNA polymerase region) were extended by an additional 9.6 and $3.6 \mathrm{kbp}$, respectively. Recently, additional sequences from the gene cluster region have been reported (19). The sequences from the present study were included in the analysis, and the gene composition was the same. Genome walking applications are also useful to obtain unknown sequences adjacent to known sequences (19). By using these methods, more information about ' $\mathrm{Ca}$. Liberibacter asiaticus' will continue to accumulate.

Genetic diversity in bacteria can be assessed by examining specific restriction enzyme sites, repetitive elements, amplicons produced by random primers, or genome sequences (22). There
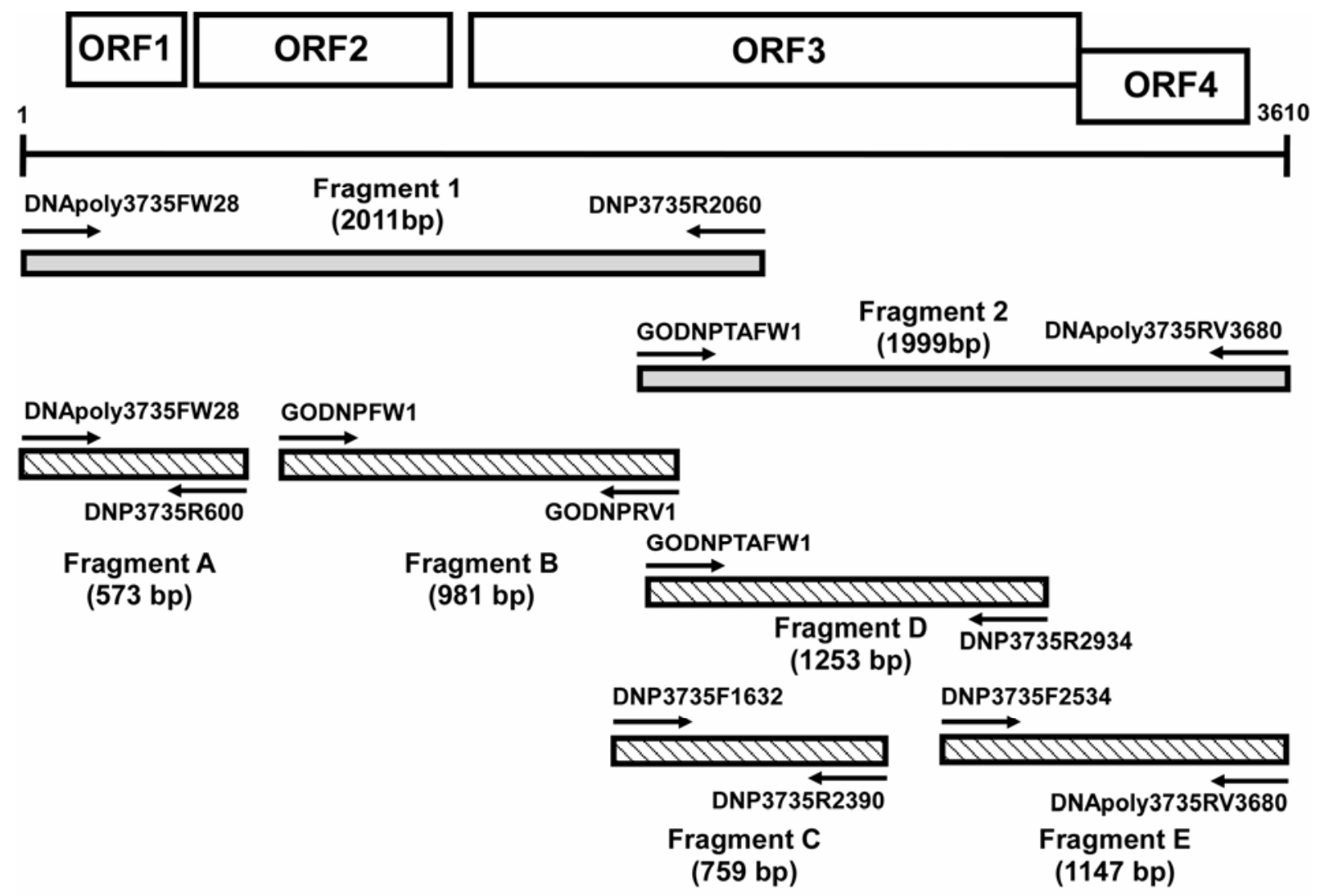

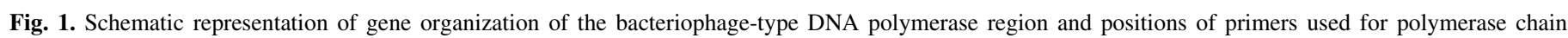

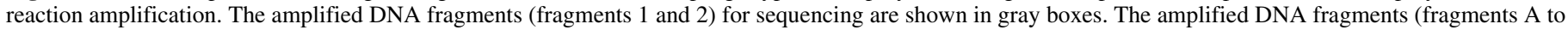

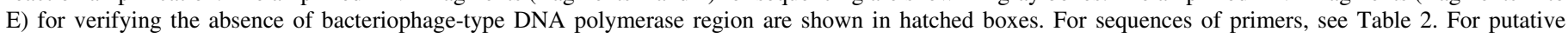
products of open reading frames (ORFs), see Table 4. 
have only been a few reports of the genetic diversity among ' $\mathrm{Ca}$. Liberibacter asiaticus' isolates. In these reports, only one DNA fragment has been investigated in several isolates from a limited geographical area $(3,10,24,29)$. It has been reported that the $16 \mathrm{~S}$ rDNA and the $16 \mathrm{~S} / 23 \mathrm{~S}$ intergenic spacer regions are highly conserved among isolates in Southeast Asia (29). Among the 31 isolates sequenced in the present study, no nucleotide differences were observed, which confirms the previous results. The highly conserved nucleotide sequence among the ' $C a$. Liberibacter asiaticus' isolates in the $16 \mathrm{~S}$ rDNA and $16 \mathrm{~S} / 23 \mathrm{~S}$ intergenic spacer region can be useful for developing detection methods. For example, the conservation of nucleotide sequences was indispensable when gene diagnosis was performed using the PCR and LAMP methods, as reported by Okuda and colleagues (24).

The isolates used in this study originated from Southeast Asian countries, including Indonesia, Thailand, Vietnam, Taiwan, and Japan. The nucleotide sequences of all four regions' fragments analyzed suggest that Southeast Asian isolates of ' $\mathrm{Ca}$. Liberibacter asiaticus' are remarkably different from the India-Poona isolates. The differences in the bacteriophage-type DNA polymerase region are especially striking. Among the Southeast Asian isolates, the nucleotide sequences in the $5^{\prime}$ region of the bacteriophage-type DNA polymerase region (positions 1 to 600) can be classified into two groups (A and B). The nucleotide sequences of the group $\mathrm{C}$ isolates Thail and VN50 have chimera-like nucleotide sequences, which were possibly produced as a result of recombination. However, no evidence of recombination was observed in this study, because this region did not have adequate polymorphisms to allow statistical analysis of recombination (data not shown). One nucleotide deletion at position 486 was common among the isolates in group B, which included most of the Vietnamese and Taiwanese isolates. The nucleotide differ- ences unique to one isolate observed in the $3^{\prime}$ region of the bacteriophage-type DNA polymerase region reflected the intragroup relationships analyzed in this study (Fig. 3). This is the first evidence of nucleotide differences unique to one isolate in this gene region of ' $\mathrm{Ca}$. Liberibacter asiaticus'. These differences may be useful for monitoring the movements of ' $\mathrm{Ca}$. Liberibacter asiaticus' in the field. Some isolates could not be differentiated from the others, and further investigation is needed to explore more genetic markers. This is especially true for the Japanese isolates, which apparently lack the bacteriophage-type DNA polymerase region. In the expanded bacteriophage-type DNA polymerase sequences, ORF3, which was completely sequenced in this study, was predicted to code for a phage-type DNA polymerase. The bacteriophage-derived genes have been found in the genome of one of the citrus pathogenic bacteria, Xylella fastidiosa (4,5). Moreover, a comparative analysis of the complete genomes of $X$. fastidiosa strains revealed that some strains lack bacteriophage-related genes. This is considered direct evidence of phage-mediated horizontal gene transfer (28). Existence of a homologous gene suggests that a similar gene transfer occurred in the evolutionary history of ' $\mathrm{Ca}$. Liberibacter asiaticus'.

On the basis of sequence differences in the four regions determined in this study, ' $\mathrm{Ca}$. Liberibacter asiaticus' can be classified into five groups. The first group, group A, consists of mainly Indonesian isolates. Group B consists of mainly Vietnamese and Taiwanese isolates. These two groups include the majority of ' $\mathrm{Ca}$. Liberibacter asiaticus' isolates from Southeast Asia. The third group, group $\mathrm{C}$, included isolates Thai1 and VN50. The fourth group most likely includes the India-Poona isolate. Using the sequence information from the India-Poona isolate, the partial sequence of the bacteriophage-type DNA
A

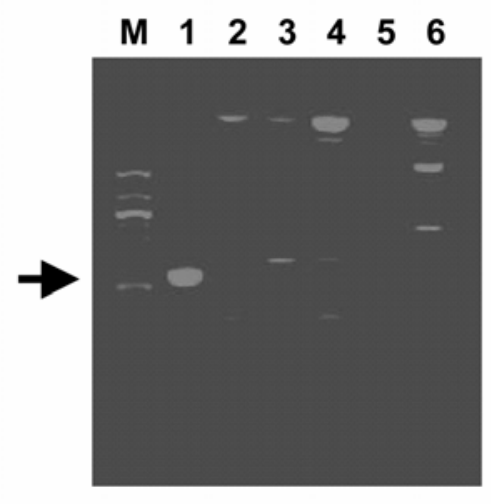

D

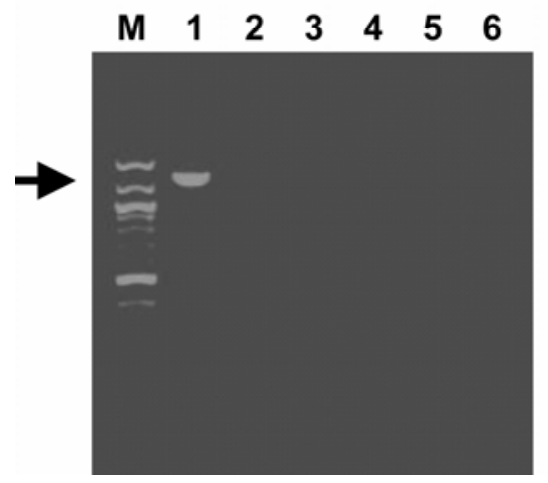

B

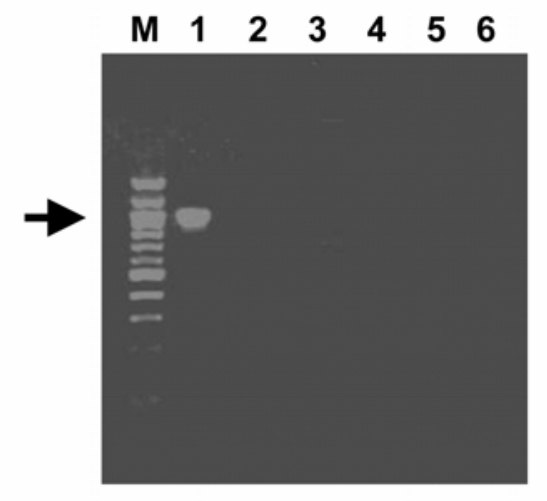

E

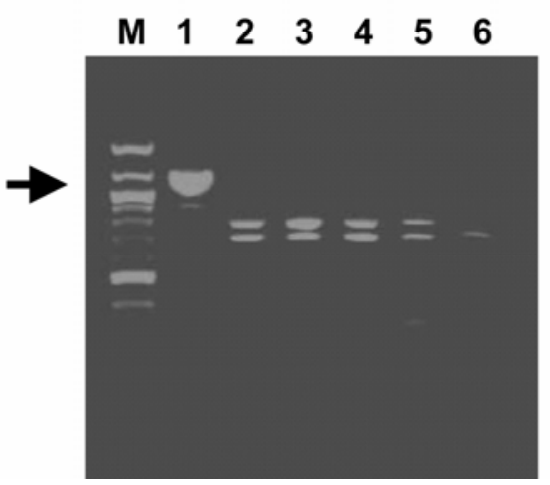

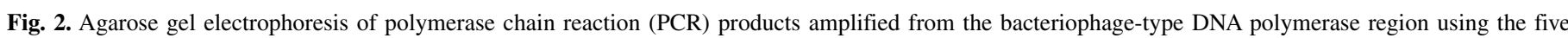

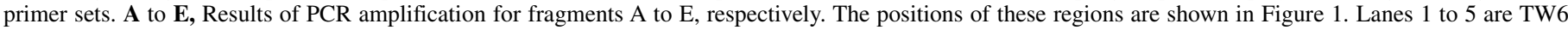

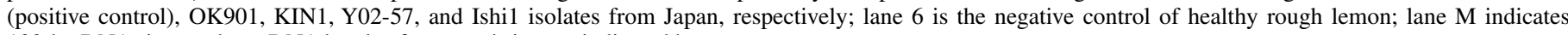
100-bp DNA size markers. DNA bands of expected size are indicated by arrows. 


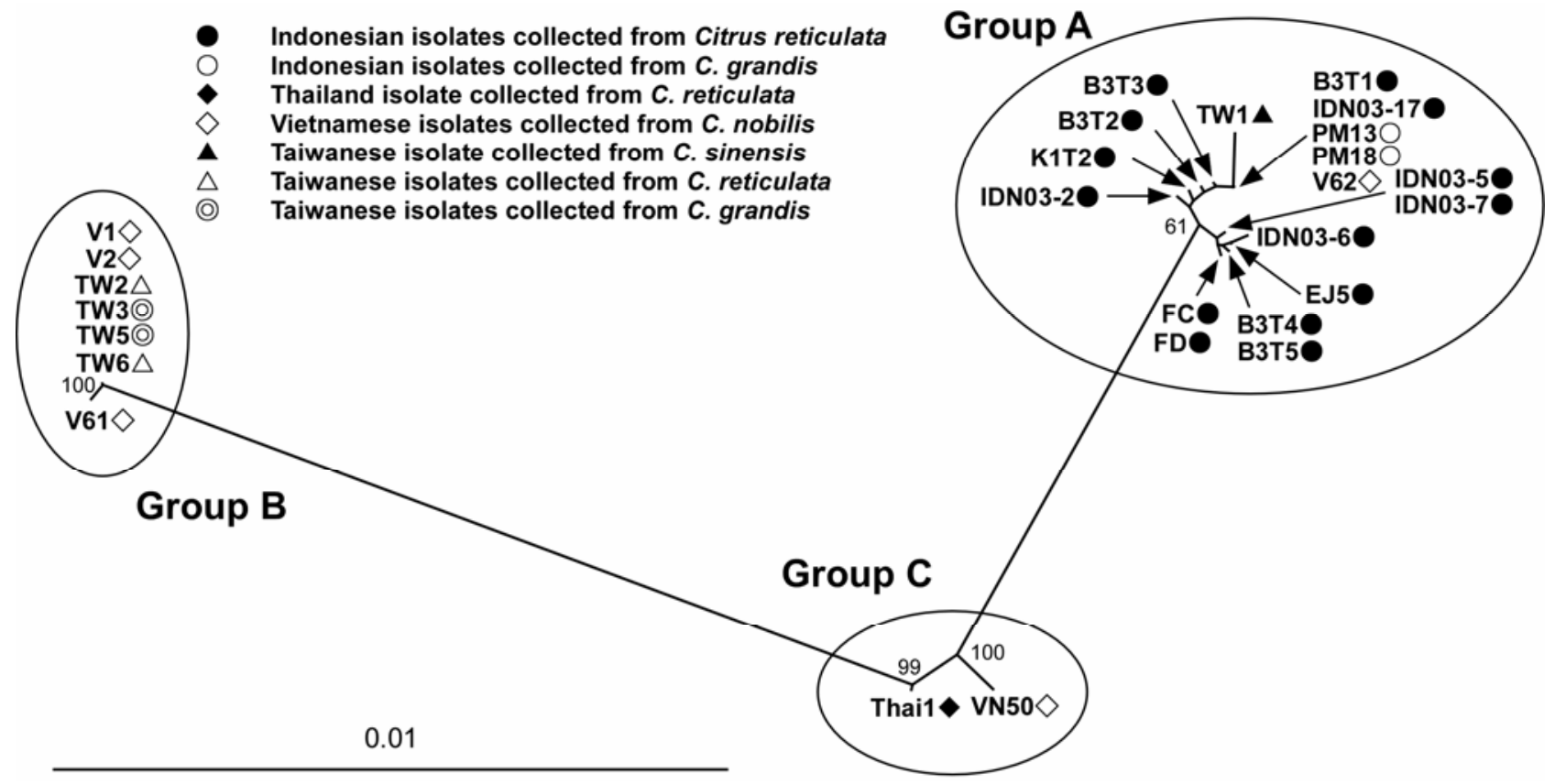

Fig. 3. Neighbor-joining tree calculated from 27 isolates of the bacteriophage-type DNA polymerase region sequences of 'Candidatus Liberibacter asiaticus'. Numbers at each node indicate the percentage of supporting bootstrap samples (only values $>60$ are shown). Branch length is drawn to scale with the bar indicating 0.01 nucleotide replacements per site.

TABLE 3. Open reading frames (ORFs) predicted from the bacteriophage-type DNA polymerase region sequences obtained from 27 'Candidatus Liberibacter asiaticus' isolates

\begin{tabular}{|c|c|c|c|c|c|c|c|}
\hline ORF & Start & Stop & $\begin{array}{l}\text { No. of } \\
\text { codon }\end{array}$ & $\begin{array}{l}\text { Most closely related GenBank } \\
\text { entries (GenBank accession no.) }\end{array}$ & $\begin{array}{l}\text { Blastx E } \\
\text { value }\end{array}$ & $\begin{array}{l}\text { Putative } \\
\text { product }\end{array}$ & $\begin{array}{l}\text { Gene product showing amino acid sequence } \\
\text { similarities with ORF found in this study }\end{array}$ \\
\hline 1 & 181 & 480 & 100 & $\begin{array}{l}\text { Deep-sea thermophilic Geobacillus } \\
\text { bacteriophage GVE2 ORF31 } \\
\text { (DQ453159) }\end{array}$ & 0.17 & Unknown & $\begin{array}{l}\text { N-terminal region (amino acids } 10-180 \text { ) had } 36 \% \\
\text { amino acid similarity with GVE2. }\end{array}$ \\
\hline 2 & 502 & 1,149 & 216 & 'Ca. Liberibacter asiaticus' (M94320) & $5 e-60$ & Unknown & $\begin{array}{l}\text { Also similar to the P50 of Acyrthosiphon pisum } \\
\text { bacteriophage (APSE- } 1 \text { and } 2)(E=2 \mathrm{e}-10 \text { and e-10, } \\
\text { respectively). }\end{array}$ \\
\hline 3 & 1,156 & 3,180 & 675 & $\begin{array}{l}\text { Bordetella phage BPP-1 bpp } 42 \\
\text { (AY029185) }\end{array}$ & e-121 & $\begin{array}{l}\text { DNA } \\
\text { polymerase }\end{array}$ & $\begin{array}{l}\text { Also similar to the phage-related DNA polymerase } \\
\text { from Xylella fastidiosa strains (E } \leq \mathrm{e}-112 \text { ) and } \\
\text { Candidatus Liberibacter asiaticus (partial } 206 \text { amino } \\
\text { acids; } \mathrm{E}=\mathrm{e}-106 \text { ). }\end{array}$ \\
\hline 4 & 3,180 & 3,488 & 103 & $\begin{array}{l}\text { Bordetella phage BPP-1 bpp } 43 \\
\text { (AY029185) }\end{array}$ & $5 e-11$ & Unknown & $\begin{array}{l}\text { Also similar to the phage-related or VRR_NUC } \\
\text { domain from Xyllela fastidiosa strains }(\mathrm{E} \leq 4 \mathrm{e}-8) \text {. }\end{array}$ \\
\hline
\end{tabular}

polymerase region was compared. Remarkable sequence differences were observed in this region. These striking differences were not observed among the Southeast Asian isolates sequenced in this study. The fifth ' $C a$. Liberibacter asiaticus' group included four Japanese isolates, which lack the bacteriophage-type DNA polymerase region, that were unique from the others. The phylogenetic relationships of the Japanese isolates cannot yet be determined because a highly variable DNA fragment, such as the bacteriophage-type DNA polymerase, has not been found. Future research will include a search for a new variable DNA fragment that can be used to distinguish Japanese isolates from each other.

Citrus cultivars show different degrees of susceptibility to citrus greening (9). In general, sweet orange (Citrus sinensis) and mandarin $(C$. reticulata $)$ are the most susceptible, and pummelo (C. grandis) and rough lemon ( $C$. jambhiri) are tolerant. ' $C a$. Liberibacter asiaticus' isolates were collected from several Southeast Asian countries, and this study was performed to examine the correlation between citrus host cultivars and ' $\mathrm{Ca}$. Liberibacter asiaticus' genome sequences (Fig. 3). In this study, a correlation between Indonesian isolates collected from mandarin and pummelo was investigated. All of these Indonesian ' $\mathrm{Ca}$. Liberibacter asiaticus' belonged to group A. The result suggested that the population structure of Indonesian ' $\mathrm{Ca}$. Liberibacter asiaticus' is homogeneous, regardless of the type of citrus host and location. No genetic evidence for a host determinant was found in ' $\mathrm{Ca}$. Liberibacter asiaticus' isolates. For the other countries (Vietnam, Thailand, Taiwan, and Japan), there were not sufficient numbers of isolates to allow a conclusion about the relationships between genotype and citrus host cultivar to be made. Further investigation is necessary to explore for genes that are closely associated with the pathogenicity of ' $\mathrm{Ca}$. Liberibacter asiaticus'.

\section{ACKNOWLEDGMENTS}

We thank K. Kawabe of Japan International Research Center for Agricultural Sciences for providing the Vietnamese isolate of ' $\mathrm{Ca}$. Liberibacter asiaticus' and S. Tatineni (University of Nebraska) and W. O. Dawson (University of Florida) for valuable critical advice.

\section{LITERATURE CITED}

1. Altschul, S., Madden, T., Schäffer, A., Zhang, J., Zhang, Z., Miller, W., and Lipman, D. 1997. Gapped BLAST and PSI-BLAST: A new generation of protein database search programs. Nucleic Acids Res. 25:3389-3402.

2. Aubert, B. 1987. Trioza erytreae Del Guercio and Diaphorina citri Kuwayama (Homoptera: Psylloidea), the two vectors of citrus greening 
disease: Biological aspects and possible control strategies. Fruits 42:149162.

3. Bastianel, C., Garnier-Semancik, M., Renaudin, J., Bove, J. M., and Eveillard, S. 2005. Diversity of "Candidatus Liberibacter asiaticus," based on the omp gene sequence. Appl. Environ. Microbiol. 71:64736478.

4. Bhattacharyya, A., Stilwagen, S., Ivanova, N., D’Souza, M., Bernal, A., Lykidis, A., Kapatral, V., Anderson, I., Larsen, N., Los, T., Reznik, G., Selkov, E. J., Walunas, T., Feil, H., Feil, W., Purcell, A., Lassez, J., Hawkins, T., Haselkorn, R., Overbeek, R., Predki, P., and Kyrpides, N. 2002. Whole-genome comparative analysis of three phytopathogenic Xylella fastidiosa strains. Proc. Natl. Acad. Sci. USA 99:12403-12408.

5. Bhattacharyya, A., Stilwagen, S., Reznik, G., Feil, H., Feil, W., Anderson, I., Bernal, A., D'Souza, M., Ivanova, N., Kapatral, V., Larsen, N., Los, T., Lykidis, A., Selkov, E. J., Walunas, T., Purcell, A., Edwards, R., Hawkins, T., Haselkorn, R., Overbeek, R., Kyrpides, N., and Predki, P. 2002. Draft sequencing and comparative genomics of Xylella fastidiosa strains reveal novel biological insights. Genome Res. 12:1556-1563.

6. Bove, J. M. 2006. Huanglongbing: A destructive, newly-emerging, century-old disease of citrus. J. Plant Pathol. 88:7-37.

7. Boyd, E. F., and Brüssow, H. 2002. Common themes among bacteriophage-encoded virulence factors and diversity among the bacteriophages involved. Trends in Microbiol. 10:521-529.

8. Coletta, H. D., Takita, M. A., Targon, M., and Machado, M. A. 2005. Analysis of $16 \mathrm{~S}$ rDNA sequences from citrus huanglongbing bacteria reveal a different " $\mathrm{Ca}$. Liberibacter" strain associated with citrus disease in Sao Paulo. Plant Dis. 89:848-852.

9. da Graça, J. V. 1991. Citrus greening disease. Annu. Rev. Phytopathol. 29:109-136.

10. Deng, X., Chen, J., Feng, Z., Shan, Z., Guo, H., Zhu, J., Li, H., and Civerolo, E. L. 2008. Identification and characterization of the Huanglongbing bacterium in pummelo from multiple locations in Guangdong, P. R. China. Plant Dis. 92:513-518.

11. Felsenstein, J. 1985. Confidence limits on phylogenies: an approach using the bootstrap. Evolution 39:783-791.

12. Felsenstein, J. 1993. PHYLIP (Phylogeny Interference Package), Version 3.5. Department of Genetics, University of Washington, Seattle.

13. Halbert, S. E., and Manjunath, K. L. 2004. Asian citrus psyllids (Sternorrhyncha: Psyllidae) and greening disease of citrus: a literature review and assessment of risk in Florida. Fla. Entomol. 87:330-353.

14. Hall, T. A. 1999. BIOEDIT: A user-friendly biological sequence alignment editor and analysis program for Windows 95/98/NT. Nucleic Acids Symp. Ser. 41:95-98

15. Jagoueix, S., Bove, J. M., and Garnier, M. 1994. The phloem-limited bacterium of greening disease of citrus is a member of the $\alpha$ subdivision of the proteobacteria. Int. J. Syst. Bacteriol. 44:379-386.

16. Jagoueix, S., Bove, J. M., and Garnier, M. 1997. Comparison of the $16 \mathrm{~S} / 23 \mathrm{~S}$ ribosomal intergenic regions of "Candidatus Liberobacter asiaticum" and "Candidatus Liberobacter africanum," the two species associated with citrus huanglongbing (greening) disease. Int. J. Syst. Bacteriol. 47:224-227.

17. Jeanmougin, F., Thompson, D., Gouy, M., Higgins, D. G., and Gibson, T. 1998. Multiple sequence alignment with Clustal X. Trends in Biochem. Sci. 23:403-405.

18. Kimura, M. 1980. A simple method for estimating evolutionary rates of base substitutions through comparative studies of nucleotide sequences. J. Mol. Evol. 16:111-120.

19. Lin, H., Doddapaneni, H., Bai, X., Yao, J., Zhao, X., and Civerolo, E. 2008. Acquisition of uncharacterized sequences from 'Candidatus Liberibacter', an unculturable bacterium, using an improved genomic walking method. Mol. Cell. Probes 22:30-37.

20. Liu, M., Gingery, M., Doulatov, S., Liu, Y., Hodes, A., Baker, S., Davis, P., Simmonds, M., Churcher, C., Mungall, K., Quail, M., Preston, A., Harvill, E., Maskell, D., Eiserling, F., Parkhill, J., and Miller, J. 2004.
Genomic and genetic analysis of Bordetella bacteriophages encoding reverse transcriptase-mediated tropism-switching cassettes. J. Bacteriol. 186:1503-1517.

21. Liu, Y., and Whittier, R. 1995. Thermal asymmetric interlaced PCR: automatable amplification and sequencing of insert end fragments from P1 and YAC clones for chromosome walking. Genomics 25:674-681.

22. Louws, F. J., Rademaker, J. L. W., and de Bruijn, F. J. 1999. The three Ds of PCR-based genomic analysis of phytobacteria: diversity, detection, and disease diagnosis. Annu. Rev. Phytopathol. 37:81-125.

23. Miyakawa, T., and Tsuno, K. 1989. Occurrence of citrus greening disease in the southern islands of Japan. Ann. Phytopathol. Soc. Jpn. 55:667-670.

24. Okuda, M., Matsumoto, M., Tanaka, Y., Subandiyah, S., and Iwanami, T. 2005. Characterization of the tufB-secE-nusG-rplKAJL-rpoB gene cluster of the citrus greening organism and detection by loop-mediated isothermal amplification. Plant Dis. 89:705-711.

25. Page, R. D. M. 1996. TreeView: An application to display phylogenetic trees on personal computers. Comp. Appl. Biosci. 12:357-358.

26. Saitou, N., and Nei, M. 1987. The neighbor-joining method: a new method for reconstructing phylogenetic trees. Mol. Biol. Evol. 4:406-425.

27. Sechler, A., Schuenzel, E. L., Cooke, P., Donnua, S., Thaveechai, N., Postnikova, E., Stone, A. L., Schneider, W. L., Damsteegt, V. D., and Schaad, N. W. 2009. Cultivation of 'Candidatus Liberibacter asiaticus', 'Ca. L. africanus', and 'Ca. L. americanus' associated with Huanglongbing. Phytopathology 99:480-486.

28. Simpson, A. J. G., Reinach, F. C., Arruda, P., Abreu, F. A., Acencio, M., Alvarenga, R., Alves, L. M. C., Araya, J. E., Baia, G. S., Baptista, C. S., Barros, M. H., Bonaccorsi, E. D., Bordin, S., Bove, J. M., Briones, M. R. S., Bueno, M. R. P., Camargo, A. A., Camargo, L. E. A., Carraro, D. M., Carrer, H., Colauto, N. B., Colombo, C., Costa, F. F., Costa, M. C. R., Costa-Neto, C. M., Coutinho, L. L., Cristofani, M., Dias-Neto, E., Docena, C., El-Dorry, H., Facincani, A. P., Ferreira, A. J. S., Ferreira, V. C. A., Ferro, J. A., Fraga, J. S., Franca, S. C., Franco, M. C., Frohme, M., Furlan, L. R., Garnier, M., Goldman, G. H., Goldman, M. H. S., Gomes, S. L., Gruber, A., Ho, P. L., Hoheisel, J. D., Junqueira, M. L., Kemper, E. L., Kitajima, J. P., Krieger, J. E., Kuramae, E. E., Laigret, F., Lambais, M. R., Leite, L. C. C., Lemos, E. G. M., Lemos, M. V. F., Lopes, S. A., Lopes, C. R., Machado, J. A., Machado, M. A., Madeira, A., Madeira, H. M. F., Marino, C. L., Marques, M. V., Martins, E. A. L., Martins, E. M. F., Matsukuma, A. Y., Menck, C. F. M., Miracca, E. C., Miyaki, C. Y., Monteiro-Vitorello, C. B., Moon, D. H., Nagai, M. A., Nascimento, A., Netto, L. E. S., Nhani, A., Nobrega, F. G., Nunes, L. R., Oliveira, M. A., de Oliveira, M. C., de Oliveira, R. C., Palmieri, D. A., Paris, A., Peixoto, B. R., Pereira, G. A. G., Pereira, H. A., Pesquero, J. B., Quaggio, R. B., Roberto, P. G., Rodrigues, V., Rosa, A. J. D., de Rosa, V. E., de Sa, R. G., Santelli, R. V., Sawasaki, H. E., da Silva, A. C. R., da Silva, A. M., da Silva, F. R., Silva, W. A., da Silveira, J. F., Silvestri, M. L. Z., Siqueira, W. J., de Souza, A. A., de Souza, A. P., Terenzi, M. F., Truffi, D., Tsai, S. M., Tsuhako, M. H., Vallada, H., Van Sluys, M. A., Verjovski-Almeida, S., Vettore, A. L., Zago, M. A., Zatz, M., Meidanis, J., Setubal, J. C., and Xylella fastidiosa Consortium, O. 2000. The genome sequence of the plant pathogen Xylella fastidiosa. Nature 406:151-157.

29. Subandiyah, S., Iwanami, T., Tsuyumu, S., and Ieki, H. 2000. Comparison of $16 \mathrm{~S}$ rDNA and $16 \mathrm{~S} / 23 \mathrm{~S}$ intergenic region sequences among citrus greening organisms in Asia. Plant Dis. 84:15-18.

30. Tsai, C. H., Hung, T. H., and Su, H. J. 2008. Strain identification and distribution of citrus Huanglongbing bacteria in Taiwan. Bot. Stud. 49:4956.

31. Villechanoux, S., Garnier, M., Laigret, F., Renaudin, J., and Bové, J. M. 1993. The genome of the non-cultured, bacterial-like organism associated with citrus greening disease contains the nusG-rplKAJL-rpoBC genecluster and the gene for a bacteriophage type DNA polymerase. Curr. Microbiol. 26:161-166.

32. Weisburg, W., Barns, S., Pelletier, D., and Lane, D. 1991. 16S Ribosomal DNA amplification for phylogenetic study. J. Bacteriol. 173:697-703. 